\title{
DESCENTRANDO OS ESTADOS UNIDOS NOS ESTUDOS SOBRE NEGRITUDE NO BRASIL*
}

\section{Patricia de Santana Pinho}

\section{Entre o passado africano e o futuro norte-americano}

A noção de que a experiência negra dos Estados Unidos seria mais "moderna" que a brasileira encontra respaldo nas formulações teóricas de cientistas sociais brasileiros e norte-americanos. Discute-se até mesmo a idéia de que os afro-americanos dos Estados Unidos deveriam intercambiar sua negritude (blackness) - representada por uma identidade racial politizada e moderna - pela afri-

* Uma primeira versão deste artigo foi apresentada no seminário temático "Da modernidade global às modernidades múltiplas: descentrando a teoria social", coordenado por Josué Pereira da Silva (Unicamp) e Sérgio Costa (FU-Berlin), no XXVIII Encontro Anual da Anpocs, 2004.

Artigo recebido em novembro/2004

Aprovado em agosto/2005 canidade (africanness ou africanity) dos negros brasileiros, ou seja, sua suposta capacidade de retenção da cultura "original africana" (Walker, 2002). Se Walker (Idem) defende explicitamente a troca de blackness por africanness e Christmas (1992) se deslumbra com o rico "cardápio" de tradições africanas "preservadas" pelos negros no Brasil, há autores afro-americanos que, ao contrário, não só não se entusiasmam com o que vêem como "excesso" de culturalismo na negritude brasileira como ainda recomendam o aprendizado nos moldes da negritude estadunidense moderna (Hanchard, 1994; Gilliam, 1992).

Essas argumentações variadas possuem em comum as dicotomias tradição versus modernidade, cultura versus política, atraso versus avanço, além de uma (implícita) noção evolucionista de negritude. A abundância de recursos materiais e intelectuais da academia estadunidense explica, em grande parte, a presença e o predomínio das suas idéias nos meios acadêmicos latino-americanos. Contudo, é necessá- 
rio levar em conta também a relação entre a posição de cada país na configuração global de poder e a capacidade de alcance e influência da suas idéias e teorias. Essa desigualdade de acesso às correntes mundiais de poder explica, ao menos em parte, a tendência de se comparar o Brasil aos Estados Unidos. Dessa maneira, embora o Brasil tenha muito mais em comum com outros países latino-americanos - a exemplo de Cuba e Venezuela, que também possuem narrativas de miscigenação e de "mitificação da miscigenação" -, a política racial brasileira ainda é predominantemente comparada com a norte-americana.

$\mathrm{Na}$ construção das organizações negras brasileiras, há uma forte influência do movimento negro dos Estados Unidos e do modelo separatista norte-americano de contestação. Contudo, o modelo de sociedade multiculturalista colocado em prática nos Estados Unidos tem sido criticado por estabelecer "identidades enlatadas e comercializáveis dos étnicos como consumidores rotuláveis" (Segato, 1998), em que o valor social do cidadão e do consumidor nem sempre convergem. Segato explica ainda que autores como Bhabha (1992) têm apontado para o regime forçado, e de certa forma vazio, da etnicidade norte-americana, e outros têm enfatizado como a classificação norte-americana de linhagens em termos de etnicidade serve para manter as fronteiras no lugar, consistindo em um modelo liberal de multiculturalismo, em que a idéia de diversidade é inerte.

Para a filósofa Wendy Brown (1995), a proliferação e a politização das identidades não refletem escolhas políticas ou morais, mas uma complexa produção histórica que tem construído a maioria de nós como marginais, desviantes ou subumanos. A construção das nossas identidades como sendo marginais é constitutiva da centralidade e da legitimação do poder do próprio centro. Para Brown, é o poder disciplinador, explicado por Foucault (1999), que produz as identidades sociais no contexto do Estado liberal. O exemplo mais emblemático dessa produção regulada das identidades poderia ser encontrado na sociedade estadunidense dominada pelo welfare, que cria welfare subjects, subdividindo-os nas categorias "raça", "gênero", "geração", "orientação sexual" etc. Dessa maneira, as identidades políticas seriam produzidas não apenas através dessas categorias, mas enquanto essas categorias, reduzindo assim as identidades ao âmbito dos interesses.
Brown descreve o caráter traumatizado dos desejos existentes nas identidades politizadas, ${ }^{1}$ afirmando que as demandas reguladoras do Estado encorajam a formação das identidades fundadas na dor, estimulando as categorias marginalizadas que teriam o status da ferida, reforçando, por conseguinte, o ideal masculino burguês de igualdade, que tem como referência o homem branco heteressexual. Nesse sentido, enquanto a igualdade for compreendida a partir dos moldes limitados do liberalismo, as identidades politizadas não realizarão a crítica do capitalismo, atuando, em vez disso, no sentido de fortalecê-lo, uma vez que brigam pelas migalhas que caem da mesa do "poder central".

Desde a década de 1970, percebe-se nos discursos do movimento negro brasileiro contemporâneo ${ }^{2}$ uma grande influência exercida pelo movimento negro estadunidense. A tentativa de adoção de uma classificação racial bipolarizada, em voga nos Estados Unidos, ${ }^{3}$ é um dos exemplos mais emblemáticos dessa influência nada recíproca. Evidentemente, buscar essa classificação racial binária, que opõe negros e brancos, e exclui a possibilidade de variação cromática entre os dois extremos, tem representado uma tentativa de combater a celebração da mestiçagem brasileira, entendida - a meu ver, indevidamente - como "máscara" que procuraria esconder os conflitos raciais. ${ }^{4}$

A reivindicação de movimentos negros brasileiros para que se adote uma classificação racial inspirada no modelo posto em prática nos Estados Unidos tem importantes conseqüências políticas. Há uma grande controvérsia entre os estudiosos da questão racial no Brasil a respeito da adoção ou não da classificação binária norte-americana. Alguns autores, como A. S. Guimarães (1995) e Hanchard (1994), defendem que o Brasil se inspire mais nos modelos dos Estados Unidos, visto que aqui a cor também seria uma categoria racial central. ${ }^{5}$

Por outro lado, há intelectuais que se posicionam de forma contrária à adoção do modelo racial norte-americano no Brasil (Fry, 1995; Segato, 1998). Sobre a bipolaridade reivindicada pelo movimento negro, por exemplo, Fry (1995/1996) explica que se trata de uma idéia impositiva e contrária àquilo que ele define como "o modo múltiplo de classificação" brasileiro. Este possibilita que indivíduos possam ser classificados de distintas maneiras, a depender da situação, o que, para Fry, 
permite uma "desracialização" da identidade individual. É uma forma de classificação que se baseia na aparência física da pessoa e não necessariamente na sua ascendência, confirmando a teoria de Oracy Nogueira (1985) de que no Brasil se privilegia mais a "marca" do que a "origem", quando se trata de classificar racialmente as pessoas.

Ironicamente, a definição pela "marca", isto é, pela aparência - acima de tudo pela cor - para afirmar quem é negro no Brasil é um ponto de consenso mesmo dentro da maioria das organizações negras brasileiras. Embora o movimento negro reivindique o mulato para as suas fileiras, o próprio movimento exige que ele tenha pele escura, ao contrário do que ocorre nos Estados Unidos, onde mestiços afrodescendentes de pele clara são considerados negros e onde a expressão light skinned blacks (negros de pele clara) não soa como uma contradição em termos. É compreensível, contudo, que o movimento negro no Brasil não visualize os mestiços e mulatos de pele clara como sendo negros, afinal esses indivíduos sofrem infinitamente menos discriminação do que aqueles de pele mais escura. No entanto, essas formas de classificação confirmam o argumento de que, acima de tudo, é o racismo que determina a "raça" do indivíduo, além de apontar para a dificuldade de estabelecer classificações que privilegiem a "origem racial" em um contexto predominado pela "marca".

Vários intelectuais brasileiros lamentam que, entre nós, os papéis raciais não sejam tão definidos quanto nos Estados Unidos, onde a colonização britânica implantou uma separação drástica entre negros e brancos. Até mesmo as formas de expressão do racismo variam muito dos Estados Unidos para o Brasil, também, em parte, como decorrência dos tipos diferentes de colonização. Nos Estados Unidos, existe uma definição socialmente sistematizada dos grupos étnicos, e quem tiver a mais leve ascendência negra é considerado negro, pois lá "a genética cedeu lugar a uma fantasia racial rigorosamente dicotômica" (Risério, 1995, p. 103). Em outras palavras, ainda segundo Risério, os afro-americanos constituem, biologicamente, o grupo mais heterogêneo dos Estados Unidos, mas talvez sejam, socialmente, um dos mais homogêneos; ao menos aparentemente, já que há também grandes desigualdades internas ao grupo, sobretudo em função das diferenças de classe. ${ }^{6}$

Até mesmo a segregação norte-americana tem servido como modelo para estudiosos da negritude no Brasil. O antropólogo Kabengele Munanga, por exemplo, afirma que a promoção de uma consciência étnica e política mobilizadora na população negra brasileira só é possível mediante uma autodefinição que se baseie na herança africana (história, cultura, religião etc.) e numa distinção clara entre negros e brancos. Para Munanga, "essa identidade passa por sua cor, ou seja, pela recuperação de sua negritude, física e culturalmente" (1998, p. 14). A seu ver, portanto, o negro precisa reafirmar a sua identidade a partir do passado africano e com vistas a um futuro que, no meu entender, se assemelha com o presente norte-americano. Podemos afirmar que o projeto de grande parte do movimento negro brasileiro se situa entre um "passado africano" e um "futuro norte-americano".?

A antropóloga Rita Segato (1998) critica a obediência brasileira aos padrões norte-americanos, questionando se as identidades transnacionais que estão surgindo sob as pressões da globalização seriam mesmo representativas das formas de alteridade que existem fora dos grandes centros difusores. Para a autora, os Estados Unidos têm ditado para o resto do mundo suas políticas de multiculturalismo, mas nós não precisamos segui-las. Podemos acreditar que existem outras formas de produção de subjetividades relacionadas à África e que há muitas estratégias para defender a reprodução da África no Novo Mundo.

No mesmo sentido está a crítica de Fernando Rosa Ribeiro (1997), ao afirmar que há um fio que perpassa a maior parte da imensa literatura sobre a questão racial no Brasil, qual seja, a comparação, explícita ou implícita, com a sociedade norte-americana, quase sempre acompanhada de um teor valorativo sobre as formas norte-americana e brasileira de tratar a questão racial. Essa perspectiva comparativa e valorativa está presente nas discussões sobre as mais variadas temáticas das relações raciais no Brasil, onde existiriam dois discursos distintos sobre a questão racial. A seu ver, discursos antagônicos e excludentes - o essencialista do movimento negro, pautado sobretudo na apologia ao negro norte-americano, e o acadêmico, predominantemente antiessencialista e antinorte-americano.

Se é importante evitar cair na armadilha do essencialismo, não se deve, por outro lado, chegar ao extremo oposto e concluir que qualquer dinâmica de unificação das culturas negras contemporâneas seria 
incorreta. A particularidade negra deve ser reconhecida e valorizada nas análises, pois são definidas por práticas culturais e agendas políticas que conectam os negros na diáspora. Dessa forma, é importante valorizar as tentativas de localizar as práticas culturais que vinculam os negros dispersos no Novo Mundo, na Europa e na África. Para Paul Gilroy (1993), a noção de diáspora ainda é imprescindível para se conhecer as dinâmicas éticas e políticas da história inacabada dos negros no mundo moderno. Para o autor, continua sendo fundamental pesar as similaridades e as diferenças entre as culturas negras diaspóricas.

Valorizar essas conexões, contudo, não significa que as políticas de identidade devam ser iguais para grupos negros de diferentes países, ou mesmo dentro de um único país. Se já é problemático pensar em um passado comum para todos os negros da diáspora, mais complicado ainda é acreditar que o futuro será resolvido da mesma maneira em todos os lugares. É certo que os movimentos negros norte-americanos obtiveram grandes conquistas durante as lutas pelos direitos civis, com o estabelecimento de leis como as das ações afirmativas, mas lidam também com grandes dificuldades e, acima de tudo, situam-se em um contexto bastante distinto da realidade socioracial brasileira.

Parece-me que o presente brasileiro não possui nem o conforto ilusório do passado mítico africano nem a segurança, igualmente ilusória, do modelo de sociedade "multirracial" dos Estados Unidos. A formação das idéias de diversidade, etnicidade e "raça", bem como das operações cognitivas pelas quais o racismo é exercido, se dá dentro do contexto específico de cada nação. Se há um forte componente transnacional nas identidades negras da diáspora, há também especificidades regionais e nacionais que criam formas distintas de racismo e, por conseguinte, de identidades que se constituem em grande parte a partir do racismo existente. Sabemos que o próprio processo de formação da nação é, em si, um processo de definição das "raças", ${ }^{8}$ portanto as estratégias e as políticas públicas de combate ao racismo precisam ser formuladas de acordo com tais especificidades.

\section{Salvador da Bahia como "cidade mundial" negra}

A fim de fazer uma reflexão teórica que vise a superar a centralidade dos Estados Unidos nos estudos sobre negritude, acredito ser importante recuperar a noção de diáspora africana como configuração multicentralizada. Para tanto, examino a posição de Salvador da Bahia enquanto um centro de produção cultural negra importante para o desenvolvimento de relações negras transnacionais no continente americano. Analiso as funções específicas exercidas por Salvador como uma cidade mundial negra, não apenas no estágio atual da globalização - em que a Bahia tem adquirido o status de "Meca da Negritude", atraindo um número cada vez maior de turistas afro-americanos -, mas também o papel dessa cidade na formação do mundo moderno.

Acredito que a Bahia pode ser considerada uma "cidade mundial" por haver ocupado na época colonial um espaço urbano de central importância no mundo. As cidades mundiais definemse como centros de poder cultural e político na constituição do sistema de mundo moderno. Possuem diversos significados e uma grande variedade de papéis, mas são, acima de tudo, zonas de contato, onde variados grupos se encontram e entram em conflito. Diferentemente das "cidades globais" (Sassen, 2001), conceito que enfatiza os papéis econômicos das megalópoles, as cidades mundiais caracterizam-se por sua capacidade de interferir na hierarquia global da concentração de poder e produção do conhecimento, o que Anibal Quijano (2000) denomina "colonialidade do poder". Além disso, enquanto o termo "cidade global" geralmente é usado para definir os centros econômicos do estágio atual da globalização, marcado pelo aumento do capital financeiro desde a década de 1970, as "cidades mundiais" têm sido centrais para o mundo moderno desde o começo da história do capitalismo.

Dentre os muitos lugares da diáspora negra marcados por forte presença cultural africana, a Bahia tem se destacado por possuir um grande legado de africanismos. O antropólogo Melville Herskovits, nas décadas de 1940 e 1950, encantando-se com o manancial de "reminiscências" e "retenções culturais" africanas na Bahia, classificou-a em alta posição na sua "escala 
de africanismos". O candomblé, os ritmos musicais, a capoeira e a culinária do dendê são os principais exemplos de expressões culturais de origem africana reelaborados em solo baiano e que têm servido para caracterizar a Bahia como "negra" e "africana".

Contemporaneamente, além do "estoque de africanismos" que comprovariam a continuidade histórica com a "Terra-Mãe", a aura de negritude da Bahia tem resultado também da busca pela reafirmação dos laços com a África, através de um movimento iniciado nos anos de 1970, quando eram veiculadas as notícias das lutas pró-independência das então colônias africanas, e quando ainda ecoavam as mensagens da soul music norte-americana. Foi neste contexto que os movimentos negros no Brasil começaram a buscar o fortalecimento de seus vínculos com a África, ainda que isso tenha se dado mais no plano do imaginário e da produção cultural do que na esfera da política internacional ou da diplomacia. Os elementos culturais afro-brasileiros foram então ressignificados com o intuito de reafirmar a ligação com a África-Mãe.

No interior do sistema internacional de trocas de símbolos, idéias e imagens, há vários centros emanadores de "negritude", além da própria África e dos hegemônicos Estados Unidos. Ainda restrita a um pequeno raio de alcance, mas destituída de qualquer grau de timidez, a Bahia tem despontado como um pólo produtor de símbolos negros, que aos poucos começa a ganhar espaço e afirmar sua posição nas rotas do Atlântico Negro.

A posição da Bahia como um dos centros do Atlântico Negro teve início ainda durante o período colonial, quando o tráfico de escravos inseriu definitivamente o Brasil nas redes do comércio transatlântico. Análises recentes têm mostrado que a formação do Brasil se deu muito mais em função da sua relação com a África do que com Portugal. Luís Felipe de Alencastro (2000), por exemplo, demonstra que a Bahia e o Rio de Janeiro estavam mais conectados a Luanda e Benguela do que a outras cidades brasileiras do período. Os portos baianos negociavam com navios estrangeiros muito antes da abertura oficial dos portos brasileiros. No final do século XVIII, negociantes brasileiros já dominavam o tráfico de escravos, que passou então a ser organizado a partir da Bahia, e não mais a partir de Lisboa.

O nome "Bahia" tem sido utilizado tanto por brasileiros como por estrangeiros para se referir à cidade de Salvador da Bahia de Todos os Santos, a capital do estado da Bahia. Devendo seu nome à baía em torno da qual se localiza o Recôncavo, bem como à data de todos os santos, quando foi descoberta e batizada pelos portugueses em primeiro de novembro de 1501, a cidade que aí cresceu tornou-se conhecida como Bahia. Tanto para os que vivem no interior do estado, quanto para aqueles que vivem no exterior do país, Salvador tornou-se internacionalmente conhecida como "Bahia", segundo Pierre Verger (1999a) "como se outras baías não existissem". Baseando-me nesta designação previamente estabelecida, tomo a liberdade de utilizar aqui o nome "Bahia" para me referir a Salvador e às cidades também negras do Recôncavo.

A majoritária população negra da Bahia contribuiu para que viajantes e exploradores que visitaram a cidade durante os séculos XVIII e XIX a descrevessem como uma cidade negra, apelidando-a de "Nova Guiné" e "Negrolândia" (Verger, 1999a). Mais tarde, a Bahia recebeu ainda os títulos de "Roma Negra" e "Meca da Negritude", designações que apontam para sua condição central na rede de circulação de povos e símbolos negros. "Roma Negra" e "Meca da Negritude" são termos que enfatizam claramente o caráter da Bahia como uma cidade-mundial, primeiro porque destaca sua centralidade no Atlântico Negro que, como vimos, é um sistema que permite a existência de muitos centros em sua configuração diaspórica - e, conseqüentemente, porque caracteriza a Bahia como um ponto de convergência, contato e peregrinação.

Ao longo do século XIX, alguns negros baianos emancipados passaram a participar do comércio com a África. Entre as muitas mercadorias trazidas do golfo do Benin para a Bahia, destacavam-se produtos usados no candomblé. Penas vermelhas, tinturas e tecidos eram algumas das mercadorias cobiçadas por praticantes do candomblé na Bahia, junto com a troca de recados pessoais e segredos religiosos que conectava pessoas dos dois lados do Atlântico. O intercâmbio transatlântico feito inicialmente por comerciantes ganhou novos mediadores com a entrada, no século XX, de pesquisadores, dentre os quais Pierre Verger tornou-se o mais conhecido. Transportando presentes, mensagens, objetos e segredos e servindo como um intermediário 
entre a Bahia e a África Ocidental, Verger agradou os praticantes mais puristas do candomblé, ansiosos em se reconectar com a fonte original africana, ao mesmo tempo em que desagradou os pesquisadores igualmente puristas, que acreditavam que o legado de "sobrevivências africanas" no Novo Mundo deveria ser cuidadosamente preservado de modo a ser, por intermédio de suas pesquisas, descoberto e mapeado. Melville Herskovits, por exemplo, havia ficado bastante incomodado com as perambulações de Verger e por este ficar carregando tradições de um lado ao outro do Atlântico, bagunçando assim os pedaços de seu gigantesco quebra-cabeça: seu laboratório de retenções e sobrevivências culturais. Atualmente, mães e pais de santo fazem, eles mesmos, suas próprias viagens "de volta" à África em busca das tradições perdidas. Por outro lado, religiosos do continente africano, especialmente de cultos bantu, também viajam para a Bahia para encontrar tradições que se perderam na África mas que foram preservadas nos candomblés baianos. ${ }^{\text {? }}$

Segundo Vivaldo da Costa Lima, o termo "Roma Negra" teria resultado da expressão "Roma Africana", cunhada por Mãe Aninha, fundadora do terreiro Ilê Axé Apô Afonjá. A famosa ialorixá havia declarado à antropóloga Ruth Landes nos anos de 1940 que a Bahia era a Roma Africana, não apenas por seu grande número de terreiros de candomblé, mas principalmente pela sua centralidade no culto transatlântico dos orixás. A metáfora, inspirada pela fé católica da ialorixá, expressava que, se Roma seria o centro do catolicismo, Salvador seria o centro do candomblé, portanto uma Roma africana. O termo teria sido traduzido para a língua inglesa por Ruth Landes em Cidade das mulheres, como Negro Rome e depois retraduzida para o português como "Roma Negra". ${ }^{10}$

O título de "Meca da Negritude" também deve muito à religião dos orixás e não, como poderia parecer, à grande presença de escravos muçulmanos trazidos à Bahia. Trata-se de um termo mais recente e que tem sido promovido principalmente por militantes negros e produtores culturais de outros estados do Brasil que consideram a Bahia a principal fonte de cultura africana do país. Pais e mães de santo de São Paulo e do Rio de Janeiro freqüentemente vinculam a ancestralidade de seus terreiros, bem como a sua "feitura" religiosa, a terreiros e ialorixás baianos. O mesmo acontece com grande número de academias de capoei- ra, cujos mestres associam o seu aprendizado aos velhos capoeiristas baianos como forma de conferir legitimidade ao seu jogo. Da mesma maneira, os fundadores dos primeiros blocos afro têm emprestado seus conhecimentos de cultura afro-baiana mediante serviços de consultoria a grupos culturais negros situados em outros estados do Brasil. A aura de negritude da Bahia, apesar de originada em tempos coloniais, tem sido constante e intensamente reelaborada. A década de 1970 inaugurou o processo de reafricanização nas esferas do carnaval, da música, da dança e da estética, estabelecendo a Bahia como a "Meca da Negritude", reatualizando assim seu significado como centro cultural no Atlântico Negro. ${ }^{11}$

Gilroy defende que o processo que criou o negro produziu suas próprias e específicas contradições. Assim, a música negra, as artes negras e o pensamento negro radical, seja ele político seja religioso, seriam expressões da vertente contracultural crítica do Atlântico Negro, a partir do qual se teria gerado uma contra-interpretação da modernidade. Esta vertente tem suas genealogias e pode ser mapeada historicamente, reconstruindo laços e pontos de articulação. Um dos principais aspectos dessa contracultura é a fusão de ética com estética, estimulando um contra-discurso que se posiciona para além do pressuposto ocidental da dualidade entre arte e política. ${ }^{12}$

Para visualizar a Bahia no Atlântico Negro, é necessário considerá-la tanto como receptora quanto como emissora de objetos, símbolos e idéias que circulam por estas rotas. Os blocos afro oferecem um bom exemplo dessa "via de duas mãos", já que surgiram no bojo do processo de formação de uma cultura negra internacional contemporânea, buscando as nações africanas como referência histórico-simbólica. Os blocos afro, assim como vários grupos produtores de cultura negra, utilizam símbolos importados da arena internacional de maneiras diferentes, atualizando seus significados e modificando suas mensagens. Como em outros contextos, processos de produção contra-discursiva realizam discursos estruturados de elaboração de experiência da alteridade, a partir da ressignificação de elementos da cultura popular transnacional.

É o que parece ter sido preservado da África na Bahia, que tem atraído um número cada vez maior 
de turistas negros dos Estados Unidos. Desde a década de 1970, os afro-americanos têm viajado à Bahia para encontrar "africanidade". O que começou como uma viagem informal de um grupo de amigos se transformou ao longo das últimas décadas em um mercado estruturado e organizado que inclui agências de turismo do Brasil e dos Estados Unidos. Chamo este fenômeno de "turismo de raízes", porque é desenvolvido por pessoas que viajam para encontrar suas "raízes africanas", estejam elas localizadas no continente africano ou em países da diáspora com significativas populações negras. Os "turistas de raízes" afro-americanos buscam conhecer culturas negras diaspóricas e estabelecer uma conexão com povos afrodescendentes de outras partes da diáspora. Eles visitam a Bahia a fim de conhecer de perto o que afirmam ser suas "tradições perdidas". É comum encontrá-los, com suas roupas africanizadas, tranças e turbantes, nos ensaios dos blocos afro, nos terreiros de candomblé e nos locais onde as expressões culturais afro-baianas acontecem.

Esses turistas negros vêm à Bahia com a intenção de reencontrar suas "raízes africanas", que não estariam apenas na África, mas em todos os lugares da diáspora onde a África tem sido recriada. A autora afro-americana Rachel J. Christmas, ao descrever uma dessas visitas, descreve o "pulso africano" que a Bahia oferece para os afroamericanos:

Nós sentimos o pulso africano na batida do samba, conhecido como semba em Angola; engolimolo com a comida condimentada, feita com castanhas, leite de coco, gengibre e quiabo, também usados na cozinha africana; testemunhamo-lo nas cerimônias de Candomblé, enraizado na religião dos iorubás da Nigéria; ouvimo-lo no musical sotaque iorubano do português falado no estado da Bahia. [...] Hoje, os baianos estão muito mais conscientes de suas origens do que estão os afroamericanos (Christmas, 1992, pp. 253-254). ${ }^{13}$

Por meio de sua produção cultural, os blocos afro exercem um papel fundamental nas novas formas tomadas pelo movimento negro contemporâneo, contribuindo para moldar a imagem da cidade da qual fazem parte e servindo como referência importante para outras organizações negras do Brasil e de outras partes do mundo. A estética, os ritmos musicais e diversos outros elementos que compõem as narrativas dos blocos afro certamente foram influenciados por discursos e símbolos que atravessaram o Atlântico Negro, mas é fundamental perceber que, assim como recebem influências, os blocos afro também recriam, ressignificam e produzem elementos novos que participam do cenário negro contemporâneo e internacional. Os blocos estão criando novos objetos de negritude que têm o gosto do passado, da tradição, da africanidade, correspondendo imediatamente ao que é buscado pelos turistas afro-americanos.

Exatamente por se tratar de uma troca simbólica transnacional, não podemos ignorar que a Bahia não apenas importa elementos da cultura negra universal para incorporá-los e atribuir a eles novos significados, mas está inserida no contexto da cultura negra mundial também como criadora e exportadora de símbolos étnicos negros. Nesse contexto, a cidade de Salvador tem se tornado um referencial de africanidade para negros de outros países da diáspora africana. Se, por um lado, a Bahia busca objetos negros modernos no mercado internacional, por outro, especializa-se em vender tradição.

Pode-se considerar a presença cada vez mais constante dos "turistas de raízes" como uma importante rede de circulação dos objetos da cultura negra, já que eles conferem status de modernidade e de etnicidade a expressões da cultura afro-baiana. Algumas expressões tornam-se mais étnicas do que nunca em função do carimbo batido por esses turistas sequiosos por encontrar suas raízes. Eles trazem formas de vestir, de falar e de pensar que seduzem boa parte dos negros brasileiros, e muitos fazem essas viagens com o intuito de trocar sua "modernidade" - representada principalmente pelas conquistas obtidas pelos movimentos dos direitos civis - pela "tradição" africana da Bahia - encontrada nas expressões culturais afro-baianas -, como foi explicitado por vários deles. ${ }^{14}$ Exemplo disso pode ser conferido na seguinte afirmação feita por uma turista afro-americana em uma de suas roots-trip a Cachoeira:

Nós (negros americanos e negros brasileiros) temos uma grande gama de coisas para trocar uns com os outros. Quando nós vimos para a Bahia, estamos aqui para aprender sobre a nossa própria história e nossa origem comum, porque as tradições africa- 
nas foram capazes de sobreviver aqui. Mas vocês também têm muito que aprender conosco, sobre a nossa história de direitos civis, porque, nesse ponto, estamos muito à frente de vocês. ${ }^{15}$

É importante ressaltar que embora os afroamericanos venham ao Brasil em busca do seu "passado", das suas "tradições perdidas", o processo mesmo de "invenção das tradições" representa um exemplo que caracteriza a construção das identidades como inseridas na modernidade. ${ }^{16}$ Quando uma tradição é invocada, como no caso das "tradições africanas", torna-se evidente que já se está, pelo menos parcialmente, fora dela. Ela se torna um objeto a ser retrabalhado e reinvocado. Os estudos sobre "invenções de tradições", primeiramente sistematizados por Hobsbawm e Ranger (1984) e Benedict Anderson (1989), ${ }^{17}$ têm mostrado que as tradições são criadas no presente, refletindo muito mais os interesses de um dado grupo do que uma suposta "essência cultural". ${ }^{18}$

Os movimentos negros nas Américas situamse em um contexto de emergência de novas identidades coletivas que não se limitam necessariamente ao modelo dos Estados-nação. Muitas dessas identidades, até então acanhadas, moveram-se para o centro das sociedades às quais pertencem e, freqüentemente, para a arena internacional. As novas identidades contestaram a hegemonia das identidades dominantes e passaram a exigir um espaço nas arenas institucionais, redefinindo o conceito de cidadania e dos direitos (Eisenstadt, 2000). Embora muitas vezes baseiem seu discurso na tradição, essas identidades são modernas, já que pregam a reconstrução da personalidade e das identidades individuais e coletivas por meio da ação humana consciente, da agency, vista como capaz de transformar o indivíduo e a sociedade e de estabelecer uma nova ordem social.

Eisenstadt comenta sobre o lugar comum de entendermos as influências ocidentais em países como Índia ou China como sendo a própria "chegada da modernidade". Confundimos assim Ocidente com modernidade. É possível fazer uma analogia e afirmar que, da mesma maneira, tomamos "negritude estadunidense" como sinônimo de "negritude moderna", em contraposição a outras formas de negritude, tidas como tradicionais, a exemplo das negritudes existentes na África e na
América Latina. Contudo, apesar das ideologias de pureza, as formas culturais diaspóricas não podem ser antimodernas, porque sua existência pressupõe redes transnacionais construídas a partir de múltiplos anexos formados na modernidade.

Como indica Eisenstadt (Idem), a incorporação das chamadas "idéias importadas" não precisa ser vista como imitação, já que tem possibilitado importantes inovações. Dessa maneira, os programas culturais da modernidade são reinterpretados por grupos que elaboram os seus próprios discursos, construindo-se assim múltiplas modernidades. Esses movimentos têm dissociado modernidade de ocidentalização, rejeitando o monopólio ocidental sobre a modernidade e retirando o programa cultural ocidental do posto de epítome da modernidade. Da mesma maneira, é possível dissociar a modernidade ou, no nosso caso, a negritude moderna, do monopólio estadunidense sobre a negritude.

É importante ressaltar que na troca de objetos e símbolos no sistema Atlântico Negro, há uma hierarquia que não pode ser ignorada. $O$ Brasil importa objetos negros que têm aura de modernidade e exporta objetos negros que têm aura de tradição. A globalização centra-se mais sobre trocas verticais do que horizontais.

Não obstante, por enquanto, em termos de fluxos globais de símbolos e mercadorias na base da cultura negra internacional, Salvador mantém uma posição periférica. Em relação aos centros de produção e transmissão da maioria desses símbolos e dessas mercadorias, Salvador pertence ao extremo da recepção, aos enormes interiores do Atlântico Negro. Os centros estão situados no mundo anglófono [...] (Sansone, 2000, p. 14).

Os principais motivos disso são a fraca posição do Brasil na economia mundial e na geografia do poder e o domínio norte-americano e europeu sobre a circulação mundial dos paradigmas científicos sobre "raça", numa globalização em que o Brasil ainda representa muito mais uma periferia consumidora (Idem).

Ainda assim, é preciso levar em conta que uma das principais contribuições da teoria do sistema Atlântico Negro tem sido a de revelar que a diáspora negra não tem um único centro emanador de símbolos, imagens e idéias. Além da nobreza do 
Egito e da Etiópia, e do "conhecimento fundamental" dos povos "tribais" do Oeste africano, existem outros pólos de africanidade ou, ao menos, de negritude, e eles estão localizados fora da África Mãe, ou para além da hegemonia do mundo anglófono. É importante considerar que os caminhos estão sendo abertos e que os canais de comunicação e circulação estão constantemente se criando para novas direções. Nas novas rotas que têm sido trilhadas por aqueles que buscam signos de negritude para compor suas identidades, a Bahia confirma sua condição de centro emanador de cultura negra na diáspora africana, reatualizando uma posição que, como vimos, teve início ainda no período colonial.

A radiação externa da Bahia como uma cidade mundial negra deve ser examinada então sob uma perspectiva histórico-mundial que leve em consideração os elementos de continuidade e ruptura em relação às hierarquias modernas de poder, riqueza, valorização e reconhecimento, examinando como esses elementos afetam os contextos específicos dos locais distintos em que vivem as comunidades negras. O estudo das relações negras transnacionais deve considerar o quanto a configuração global do poder interfere nas relações entre negros que vivem nos países superpoderosos e aqueles que vivem nas periferias e semiperiferias. Por isso mesmo, ao analisar as relações entre negros brasileiros e afro-americanos dos Estados Unidos, levo em consideração a dominação deste país como principal centro emanador de negritude na diáspora, além de ponderar sobre os acessos desiguais ao poder por aqueles localizados no centro e nas margens. Por outro lado, considero o turismo de raízes um canal de comunicação e troca que desafia, ao menos em parte, a supremacia dos Estados Unidos na diáspora africana, já que promove a existência de outros centros de negritude e africanidade. Como conseqüência, Salvador da Bahia, situada num país lusófono do hemisfério Sul, re-emerge como uma "cidade mundial", expandindo o mapa do Atlântico Negro ao mesmo tempo em que desafia a hierarquia de sua configuração. É exatamente esta habilidade de perturbar a colonialidade do poder que confirma seu status de cidade mundial.

\section{Conclusão}

A intenção deste artigo é contribuir para o estudo da negritude no Brasil a partir de uma perspectiva que teoriza a negritude em suas muitas e variadas versões, rejeitando a noção de que haveria uma fórmula exclusiva - ou mais avançada - de negritude. A diáspora africana moderna é marcada pela existência de vários centros emanadores de símbolos, objetos, idéias e teorias. Se conseguirmos teorizar para além da unicentralidade, nossos estudos possibilitarão substituir relações hierarquizadas por diálogos mais equilibrados.

Para Carole Boyce Davies (1999), a unicentralidade dos movimentos negros afrocentristas, isto é, a crença de que haveria um único centro do qual tudo emana, centraliza algumas experiências e marginaliza outras, sendo, portanto, passível de se transformar em projetos colonialistas e mesmo fascistas, já que a crença num único centro permite o domínio e o controle. ${ }^{19}$ Eisenstadt (2000) também aponta para o fato de que, em vários movimentos tidos como "pós-modernos" ou "multiculturais", têm se desenvolvido orientações fortemente totalitárias, a exemplo do patrulhamento do "politicamente correto".

A solução para evitar o totalitarismo seria então a defesa das variadas escolhas de pensamento e a abertura para a criação de novos paradigmas que levem em conta as desigualdades históricas, por meio de análises radicais das relações de poder. Para tanto, é preciso livrar-se da superficialidade e do maniqué́smo que geralmente imperam nos usos de expressões importantes como multiculturalismo, diversidade e multicentralidade.

A inversão de valores não significa necessariamente a transformação das relações de poder, já que o afrocentrismo, como "oposição imediata" ao eurocentrismo, não desloca os Estados Unidos da posição de centro hegemônico mundial. Ou seja, se o maior herdeiro do eurocentrismo é o "US-centrismo" (Davies, 1999), este é também o principal beneficiado do próprio afrocentrismo, já que ambos utilizam os mesmos instrumentos (mídia e mercado) para garantir aos Estados Unidos ser o centro emanador das narrativas. Um dos principais desdobramentos disso pode ser percebido nas análises feitas sobre o racismo e as rela- 
ções raciais no Brasil, nas quais a sociedade estadunidense aparece freqüentemente como o modelo a ser seguido, como o lugar onde os negros seriam mais "evoluídos", seja em termos de direitos civis, seja mesmo pelo fato de constituírem a maior classe média negra no mundo.

Ao criticar as teorias unicentristas, Paul Gilroy (1993) defende que a diáspora negra, em vez de centrada na África como terra-mãe, ou nos Estados Unidos como pólo exportador dos modelos de etnicidade, possui vários centros espalhados pelo Atlântico Negro. Em seu livro, The Black Atlantic: modernity and double consciousness, o autor desenha uma diáspora negra multicentrada e constituída por infinitas variações de cultura negra, impossíveis de serem reduzidas a tradições étnicas ou nacionais, combatendo, dessa forma, os paradigmas do "absolutismo étnico", bem como a centralidade dos discursos afro-americanos. A noção de Atlântico Negro representa, portanto, uma nova maneira de se pensar a diáspora africana em sua relação com o pensamento, a economia e a cultura ocidental.

Uma das principais contribuições desta teoria é a maneira alternativa de se entender a "diáspora", concebida como algo dinâmico que proporciona o surgimento de contra-poderes, os quais têm desafiado soberanias territoriais e crenças em identidades absolutas. Entendido dessa maneira, o conceito de diáspora permite que se possa ir além da geografia e da genealogia, da natureza e da cultura, porque rejeita a crença em nacionalidades e racialidades que seriam geradas espontaneamente, oferecendo-se como uma alternativa à noção metafísica de uma "raça" que determinaria uma suposta cultura inscrita no corpo e na cor (Gilroy, 2000, p. 123). Assim, os sentidos dinâmicos de rede de multiplicidade, comunicação e interação tornam as identidades negras explicitamente contrárias aos pensamentos nacionalistas ou aos que invocam um único centro emanador de negritude, autenticidade e verdade.

A própria idéia de modernidade carrega em si a noção de que há muito mais espaço para a agency humana e que, portanto, há muitos futuros possíveis. A atividade humana consciente é, então, vista como sendo capaz de formar e interferir na sociedade, fortalecendo a crença da realização das utopias e da construção do bem comum por meio da atividade dos indivíduos e dos grupos. Na modernidade, a definição de "bem comum" está sujeita a múltiplas interpretações e é passível de ser influenciada por grupos distintos. Além do fortalecimento da arena política, a modernidade caracteriza-se também por um modo distinto de definição das coletividades e das identidades coletivas (Eisenstadt, 2000). Inicialmente imaginadas como delimitadas às fronteiras nacionais, as identidades coletivas multiplicaram-se e expandiram-se (ou reconheceram sua expansão) para além dos limites da nação. As conexões negras transnacionais são, no meu entender, um exemplo disso.

Embora não pretenda transpor na íntegra o conceito de "modernidades múltiplas" de Eisenstadt, para quem foram desenvolvidos "tipos alternativos" de modernidade para além do Ocidente, parece-me apropriado aproveitar, para o assunto aqui tratado, a noção de que as diferentes experiências vividas (neste caso, por afrodescendentes em pontos distintos da diáspora) têm possibilitado variadas modernidades no interior do próprio mundo ocidental. A eleição da negritude estadunidense como referência máxima para se pensar a negritude no Brasil deve ser analisada como parte da nossa tendência de nos vermos a partir da margem; a princípio à margem da Europa e, contemporaneamente, à margem dos Estados Unidos. Evidentemente, a inclinação dos Estados Unidos em verem-se a si mesmos, e cada vez mais, como o centro da modernidade no mundo contemporâneo também deve ser levada em conta na análise da hegemonia norte-americana nas teorias sobre negritude no Brasil.

Se modernidade, contudo, envolve dessacralização, por que haveríamos de tornar sagrados alguns modelos e experiências em detrimentos de outros? É preciso insistir no reconhecimento da diversidade de experiências no interior da diáspora africana. Se seus pontos comuns asseguram uma certa unidade, por outro lado, as diferentes histórias vivenciadas por afro-descendentes em lugares distintos indicam a necessidade de um maior e mais equilibrado diálogo, em lugar de uma padronização linear. 


\section{Notas}

1 "Wounded character of politicized identity's desire" (Brown, 1995, p. 15).

2 Utilizo a expressão movimento negro contemporâneo para me referir às organizações negras que surgiram no Brasil a partir da década de 1970 e que têm na "raça negra" o seu caráter mobilizador e organizador. Não me refiro, portanto, a uma entidade negra em particular, mas às organizações negras brasileiras contemporâneas de uma maneira geral.

3 É importante lembrar, contudo, que a bipolaridade (negros versus brancos) não foi sempre o padrão na política racial estadunidense. Dois censos realizados no final do século XIX incluíam as classificações: "mulatto", "quarteroon" e "octoroon". Além disso, a designação "latino", existente desde a década de 1960, trouxe mudanças significativas para o sistema de classificação racial dos Estados Unidos. Agradeço ao historiador Darien Davis por estas informações.

4 Para uma crítica à noção da democracia racial como "máscara", ver Peter Fry (1982, 1991, 1995 , 1997, 2000).

5 "A importância variada da cor nas diversas regiões do Brasil assim como a sua percepção e categorização, seja no mercado de trabalho, seja nos locais de residência e de trabalho, mostram justamente que a cor nada mais é que a marca corpórea da raça, ou, para dizer de outro modo, a sua codificação. A importância da cor parece variar justamente em função do peso demográfico dos negros nas diversas regiões e nas diversas situações em que competem com os brancos" (Guimarães, 1995, p. 57).

6 A esse respeito, ver Hooks (2000), Gilroy (2000) e Appiah (1997), entre outros.

7 Sobre o passado africano, vale lembrar que os intelectuais do pan-africanismo foram os primeiros a veicular em larga escala a idéia de que os negros do mundo compartilhariam de uma mesma origem e, portanto, de um passado africano comum. Contudo, embora se posicionassem como contrários ao pensamento ocidental, os pan-africanistas adotaram as mesmas armas do Ocidente para criar uma "cultura negra/africana" que seria compartilhada por todos os negros na diáspora. As tradições inventadas, importadas da Europa, ofereceram não apenas modelos de comando aos brancos, mas forneceram a muitos africanos modelos de comportamento moderno.

8 No caso do Brasil, de uma "raça mestiça" fundada na "fábula das três raças" (Da Matta, 1984). Esse mito brasileiro pode ser considerado um paradigma de inclusão, que emana tanto por parte dos que controlam o Estado, como por aqueles que são oprimidos por ele.

9 Membros da ACBANTU (Associação Cultural de Preservação do Patrimônio Bantu), ONG baiana que tem por objetivo principal contribuir para o resgate das tradições de origem bantu e manter intercâmbio com entidades congêneres no âmbito nacional e internacional, comentaram sobre a vinda de angolanos para a Bahia, em busca de tradições bantu que foram "perdidas" na África, porém "preservadas" na Bahia.

10 Correio da Babia, 10 mar. 2004 (Andréia Santana).

11 A construção de uma imagem negra e africana da Bahia também contou com a participação de pesquisadores e escritores. Sobre a importância de Gilberto Freyre e Jorge Amado na formação da baianidade, ver Pinho (no prelo). Mais recentemente, a imagem negra da Bahia tem sido produzida também, de modo estratégico, pelo próprio Governo do Estado (ver Pinho, 2004).

12 A música e as práticas culturais e sociais de origem africana na diáspora são portadoras, ao mesmo tempo, da utopia de um mundo melhor e de uma crítica profunda ao capitalismo e ao Ocidente. O que se verifica de diversas formas, em diversos pontos do Atlântico Negro seria, então, uma interpretação baseada na separação entre política e cultura, forjada no pensamento europeu, porém distante da realidade da diáspora. O Caribe, a África, a América Latina e a América do Norte contribuíram para que se pudesse formar uma identidade racial negra transnacional. O contexto urbano, no qual suas expressões culturais foram criadas, propiciou o apelo estilístico em que se baseiam as identificações étnicas locais. A criação e as trocas transnacionais dos símbolos étnicos negros representam peças fundamentais para a constituição das 
narrativas e dos discursos de negritude com os quais os grupos negros expressam suas lutas e experiências (Gilroy, 1993).

13 A idéia de que os negros na Bahia ou no Brasil teriam mais consciência (awareness) sobre a sua origem africana está bastante presente no imaginário do militante negro norte-americano, como pode ser percebido no depoimento do rapper M1, da banda norte-americana Dead Prez: "Quando eu penso no Brasil, penso em gente preta falando português, entendeu? Eu penso em africanos, penso na África [...]. Eu sinto que eles estão mais próximos ou mais conectados à África. Eu vejo um passo ganho na força do povo preto. Na espiritualidade do povo de lá eu vejo um passo ganho na resistência contra a dominação colonial, no entendimento da importância da África, vejo uma estratégia a menos de lavagem cerebral que tem sido aplicada aqui [...]", Revista Rap Internacional, 1 (3), 2001.

14 Conforme mencionado anteriormente, a noção de que a experiência negra dos Estados Unidos seria mais "moderna" do que a brasileira encontra respaldo também em algumas formulações teóricas norte-americanas, a exemplo de Walker (2002).

15 Informações colhidas em entrevistas com turistas afro-americanos em Cachoeira - BA, ago. 2000.

16 Há que se reconhecer, portanto, os significados políticos contidos na forma como se concebem as tradições e se recria o passado. "O passado continua a nos falar. Mas já não é como um simples passado factual que se dirige a nós, pois nossa relação com ele, como a relação de uma criança com a mãe, é sempre já 'depois da separação'. É construído sempre por intermédio de memória, fantasia, narrativa e mito. As identidades culturais são os pontos de identificação, os pontos instáveis de identificação ou sutura, feitos no interior dos discursos da cultura e da história. Não uma essência, mas um posicionamento. Donde haver sempre uma política de identidade, uma política de posição, que não conta com nenhuma garantia absoluta numa 'lei de origem' sem problemas, transcendental" (Hall, 1996, p. 70).

17 Respectivamente, $A$ invenção das tradições e Comunidades imaginadas.
18 Embora amplamente adotada pela academia, a teoria da "invenção das tradições" tem recebido críticas também por parte de alguns estudiosos, que questionam, sobretudo, a autoridade do pesquisador para afirmar a "veracidade" ou não de uma tradição. Para o antropólogo Charles Briggs (1996), por exemplo, o pesquisador não tem o direito de tirar $\mathrm{O}$ poder do nativo de se autodefinir e de decidir sobre como se deve agir política e culturalmente.

19 Sobre o unicentrismo em movimentos negros, Gilroy afirma: "Temos visto que as formações autoritárias e proto-fascistas da cultura política negra do século XX têm sido constantemente estimuladas por um desejo intenso de recuperar as glórias perdidas do passado africano. O desejo de restaurar essa grandeza longínqua nem sempre tem coincidido com um entusiasmo equivalente em remediar a situação difícil da África no presente" (2000, p. 323).

\section{BIBLIOGRAFIA}

ALENCASTRO, Luiz Felipe de. (2000), O trato dos viventes: formação do Brasil no Atlântico Sul. São Paulo, Companhia das Letras.

ANDERSON, Benedict. (1989), Nação e consciência nacional. São Paulo, Ática.

APPIAH, Kwame Anthony. (1997), Na casa de meu pai: a África na filosofia da cultura. Rio de Janeiro, Contraponto.

BHABHA, Homi. (1992), “A questão do 'outro': diferença, discriminação e o discurso do colonialismo", in Heloísa Buarque de Holanda (org.), Pós-modernismo e política, Rio de Janeiro, Rocco.

BRIGGS, Charles L. (1996), "The politics of discursive authority in research on the "invention of tradition'". Cultural Anthropology, 11 (4): 435-469.

BROWN, Wendy. (1995), States of injury. Princeton, Princeton University Press.

CHRISTMAS, Rachel. (1992), "In harmony with Brazil's African pulse", in David J. Hellwig 
(ed.), African-American reflections on Brazil's racial paradise. Philadelphia, Temple University Press.

DAVIES, Carole Boyce. (1999), "Beyond unicentricity: transcultural black presences". Research in African Literature, 30 (2): 96109.

DA MATTA, Roberto. (1981), Carnavais, malandros e heróis. Rio de Janeiro, Zahar.

EISENSTADT, S. N. (2000), "Multiple modernities". Daedalus, 129 (electronic collection, A60902729, copyright American Academy of Arts and Sciences).

FOUCAULT, Michel (1999), História da Sexualidade (1) Vontade de Saber, Rio de Janeiro, Graal.

FRY, Peter. (1982), Para inglês ver. Rio de Janeiro, Zahar.

. (1991), "Politicamente correto num lugar, incorreto noutro? Relações raciais no Brasil, nos Estados Unidos, em Moçambique e no Zimbábue". Estudos Afro-Asiáticos, (21): 167-177, Rio de Janeiro.

. (1995), "O que a Cinderela negra tem a dizer sobre a 'política racial' no Brasil". Revista USP, (28): 122-135.

(1997), "Feijoada e soul food: notas sobre a manipulação de símbolos étnicos e nacionais". Ensaios de Opinião, 4.

(2000), "Politics, nationality and the meanings of 'race". Daedalus - Journal of the American Academy of Arts and Sciences, 129 (2): pp. 83-118 ("Brazil. Burden of the past: promise of the future").

GILliAM, Angela. (1992), "From Roxbury to Rioand Back in a Hurry", in David J. Hellwig (ed.), African-American reflections on Brazil's racial paradise. Philadelphia, Temple University Press.

GILROY, Paul. (1993), The Black Atlantic: modernity and double consciousness. Londres, Verso.
(2000), Against race: imagining political culture beyond the color line. Boston, Harvard University Press.

GUIMARÃES, Antônio Sérgio. (1995), "O recente anti-racismo brasileiro: o que dizem os jornais diários". Revista USP, (28): 84-95.

. (1997), "Raça, racismo e grupos de cor no Brasil". Estudos Afro-Asiáticos, (27): 45-63.

HALL, Stuart. (1992), "What is this 'black' in black popular culture?", in Gina Dent (ed.), Black popular culture, Seattle, Bay Press, pp. 21-36.

(1996), "New ethnicities", in David Morley e Kuan-Hsing Chen (ed.), Stuart hall: critical dialogues in cultural studies. Londres, Routledge, pp. 441-449.

HANCHARD, Michael. (1994), Orpheus and power: the movimento negro of Rio de Janeiro and São Paulo, Brazil, 19451988. Princeton, Princeton University Press.

HOBSBAWM, Eric \& RANGER, Terence. (1984), A invenção das tradições. Rio de Janeiro, Paz e Terra.

HOOKS, Bell. (1994), "Postmodern blackness", in Patrick Williams e Laura, Chrisman, Colonial discourse and post-colonial theory: a reader, Nova York, Columbia University Press, pp.421-427.

. (2000), Where we stand: class matters. Nova York/Londres: Routledge.

MUNANGA, Kabengele. (1998), Rediscutindo a mestiçagem no Brasil: identidade nacional $x$ identidade negra. Petrópolis, Vozes.

NOGUEIRA, Oracy. (1985), Tanto preto quanto branco: estudo de relações raciais. São Paulo, T. A. Queiroz.

PINHO, Patricia de Santana. (2004), Reinvenções da África na Babia. São Paulo, Annablume. (no prelo), "Gilberto Freyre e a baia- 
nidade", in Malcom McNee e Joshua Lund (orgs.), Gilberto Freyre e os estudos latino-americanos, Instituto Internacional de Literatura Iberoamericana/University of Pittsburgh.

QUIJANO, Anibal. (2000), "Coloniality of power, eurocentrism, and Latin America". Nepantla: Views from South, 1.3: 533-580.

RIBEIRO, Fernando Rosa. (1993), "Apartheid e democracia racial: raça e nação no Brasil e na África do Sul". Estudos Afro-Asiáticos, (24): 95-120.

. (1995), "O que é ser negro ou africano, afinal de contas?". Estudos AfroAsiáticos, (27): 203-211.

. (1997), "Ideologia nacional, antropologia e a questão racial". Estudos AfroAsiáticos, (31): 79-119.

RISÉRIO, Antônio. (1981), Carnaval Ijexá. Salvador, Corrupio.

. (1995), "Carnaval, as cores da mudança”. Afro-Ásia, (16): 90-106, Salvador.

SANSONE, Lívio. (2000), "Os objetos da cultura negra: consumo, mercantilização, globalização e a criação de culturas negras no Brasil". Revista Mana.

SASSEN, Saskia. (2001), The global city: New York, London, Tokyo. Princeton, N.J., Princeton University Press.

SEGATO, Rita. (1998), "The color-bind subject of myth; or where to find Africa in the nation". Annual Review of Anthropology, 27.

VERGER, Pierre (1981), Orixás, deuses Iorubás na África e no Novo Mundo. São Paulo, Corrupio. . (1999a), Notícias da Babia - 1850. Salvador, Corrupio.

. (1999b), Notas sobre o culto aos orixás e voduns. São Paulo, Edusp, pp. 13-34.

WALKER, Sheila. (2002), "Africanity vs blackness: race, class and culture in Brazil". NACLA, Report on the Américas, part III, vol. XXXV, maio-jun. (Racial politics, racial identities: race and racism in the Americas). 
DESCENTRANDO OS ESTADOS UNIDOS NOS ESTUDOS SOBRE NEGRITUDE NO BRASIL

Patricia de Santana Pinho

\section{Palavras-chave}

Negritude; Modernidade; Bahia; Cidade mundial; Turismo de raízes.

A predominância das perspectivas eurocêntricas ou estadunidocêntricas nas ciências sociais tem fortalecido a noção de que há um modelo exclusivo de modernidade, vivido primeiramente nos centros econômicos e, em seguida, adotado nas "periferias". Esta mesma lógica pode ser encontrada nos estudos sobre negritude no Brasil, que freqüentemente caracterizam a experiência negra estadunidense como a mais "moderna" da diáspora africana. Neste artigo, procuro fazer uma reflexão teórica que vise a superar a centralidade dos Estados Unidos nos estudos sobre negritude, recuperando a noção de diáspora africana como configuração multicentralizada. Para tanto, examinarei a posição de Salvador, Bahia, como centro importante para a formação do mundo moderno, bem como para a construção de identidades negras contemporâneas.
TAKING THE UNITED STATES OFF THE CENTER IN STUDIES ON NEGRITUDE IN BRAZIL

Patricia de Santana Pinho

\section{Keywords}

Negritude; Modernity; Bahia;

World city; Roots tourism.

The predominance of Eurocentric or US-centric perspectives in the social sciences has strengthened the belief that there is an exclusive model of modernity, experienced firstly in the economic centers of the world, and only later adopted in the 'peripheries.' The same logics can be found in studies of blackness in Brazil which have frequently characterized the black experience in the U.S.A. as the most 'modern' within the African Diaspora. In this article, I attempt a theoretical reflection which aims to overcome the centrality of the United States in the studies of negritude, recovering the notion of the African Diaspora as a multi-centered configuration. In order to do so, I examine the position of the city of Salvador da Bahia as an important center for the formation of the modern world, as well as for the construction of contemporary black identities.

\section{LA DÉCENTRALISATION DES ÉTATS-UNIS DANS LES ÉTUDES À PROPOS DE LA NÉGRITUDE AU BRÉSIL}

Patricia de Santana Pinho

\section{Mots-clés}

Négritude; Modernité; Bahia; Cité mondiale; Tourisme des racines.

La prédominance, dans les sciences sociales, des perspectives européennes ou américaines, renforce l'idée de l'existence d'un modèle exclusif de modernité, vécu tout d'abord dans les centres économiques et adopté, ensuite, par les "périphéries". Cette même logique peut être retrouvée dans les études sur la négritude au Brésil. Ces études caractérisent, fréquemment, l'expérience des Noirs aux États-Unis comme la plus "moderne" de la diaspora africaine. Dans cet article, l'auteur présente une réflexion théorique qui tente de surpasser le centralisme des ÉtatsUnis dans les études sur la négritude, en récupérant la notion de diaspora africaine en tant que configuration multicentralisée. L'article analyse également la situation de la ville de Salvador de Bahia, en tant que centre important pour la formation du monde moderne, et pour la construction d'identités noires contemporaines. 